Quality education and the role of the teacher in Fiji: mobilising global and local values

Michael Crossley ${ }^{a}$, Cresantia Frances Koya Vaka'uta ${ }^{b}$, Rosiana Lagi ${ }^{b}$, Simon McGrath ${ }^{c}$, Konai Helu Thaman ${ }^{b}$, Ledua Waqailitib

${ }^{a}$ University of Bristol, ${ }^{b}$ University of the South Pacific, ${ }^{c}$ University of Nottingham 


\title{
Quality education and the role of the teacher in Fiji: mobilising global and local values
}

\begin{abstract}
This article reports on the findings of original field research carried out in the small island developing state of Fiji, in the South Pacific. A North-South research partnership was built upon previous collaboration between team members and, in so doing, pioneered the blending of Pacific and Western research approaches sensitive to a postcolonial positioning. The study interrogates practitioner perspectives on the nature and quality of teachers and teaching in Fiji; the challenges of teachers' work and lives; priorities for successful qualitative reform; and theoretical implications for the processes of education policy transfer and qualitative improvement. The analysis draws upon work on the politics of aid and international development, revealing tensions between existing learner-centred policy frameworks and emergent neoliberal and performativity oriented initiatives influenced by international surveys of student achievement, related league tables and the experience of the regional reference societies of Australia, New Zealand and India.
\end{abstract}

\section{Key Words}

Small Island Developing States (SIDS); teachers and teaching; quality education; education policy transfer; research partnerships; Pacific values and methodologies.

\section{Introduction}

Globally, attention in the field of education and development is increasingly being focused on the challenge of meeting the new education targets enshrined in the United Nations (UN) Sustainable Development Goal 4 (UN, 2015). In the run-up to, and aftermath of, SDG4 being developed alongside the Incheon Agenda 2030 for Education (UNESCO, 2015), the international debate has shifted to an emphasis on the importance of quality learning and learning outcomes, something that had been stressed at Jomtien in 1990 but neglected until recent times. While there continues to be a right-wing attack on teachers as obstacles to improvement (e.g., Moe, 2012) and a continued faith in technological solutions that can bypass them (e.g., Negroponte, 2006), there has also been a renewed policy emphasis on the central role that teachers play in the achievement of quality education. A new wave of related OECD-based literature (e.g., McKinsey, 2007) has been supplemented by the focusing of UNESCO's 2014 Global Monitoring Report on teaching and learning - including a major emphasis on teachers' recruitment, remuneration and retention (UNESCO-GMR, 2014); and the UN Secretary-General's reaffirmation at the launch of the UN Global Initiative on Education in September 2012 of his belief in the centrality of teachers to educational improvement (Moon, 2012). This process has led to a commitment in SDG4c to:

By 2030, substantially increase the supply of qualified teachers, including through international cooperation for teacher training in developing countries, especially least developed countries and small island developing states. (UN, 2015, p. 17)

For this article, the explicit mention of small island development states (SIDS) is particularly pertinent, as we are interested in the case of Fiji - a group of islands with a population of 
less than a million people located in one of the least well documented regions of the world the South Pacific (Sharma et al., 2015). The global concerns about quality and the role of the teacher that are noted above are also manifest in Pacific Island Countries (PICs), where longstanding problems include low quality education and teachers as well as continued evidence of the poor levels of literacy, numeracy and life-skills of school leavers (PIFS, 2009, $2011,2012)$. Indeed, it may be argued that such issues have received relatively advanced attention in the Pacific Islands due to the region's high levels of achievement, in common with other SIDS, in terms of the access criteria that have dominated the Education for All (EFA) era and the education Millennium Development Goals (MDGs). Thus, we maintain that there is considerable potential for the global debate to be informed by experience in this distinctive region (Crossley et al., 2011), despite the fact that the direction of influential policy travel appears to be entirely in the opposite direction.

Globally, one well-trodden path emerging from this renewed concern about the quality of teachers and teaching is to target teacher education. This takes multiple forms: the reform of teacher education institutions; the upgrading of programmes and qualifications; changes in the length and nature of the practicum; the development of new competency standards for beginning teachers; and/or better continuous professional development for practising teachers and school administrators. In the Pacific Islands, such initiatives have also been prioritised and there has been considerable innovation around the uses of distance and flexible learning in teacher education and development (West and Daniel, 2009; Lingam et al., 2015). Practitioner challenges to international discourses promoting increased teacher accountability, and policy trajectories favouring conceptions of quality education driven by tests and assessment results, however, are also evident throughout the Pacific, based upon a mixture of informed local critique and the emergence of professional resistance to such initiatives. This is the contested nature of this distinctive and challenging small state policy context, and it is these tensions that underpin and help frame much of the research design and analysis.

\section{Research Rationale and Design}

In the light of the above issues and global trends, the research reported here was carried out between 2014 and 2016 and was jointly funded by The British Academy (BA) and The University of the South Pacific (USP). In framing the study, priority was given to establishing a sustainable international research partnership - jointly led by colleagues in Fiji and the UK who had already engaged in successful and long term collaboration. While a theoretically informed and critical analysis of this North-South research partnership will be the subject of a subsequent publication, and a later section here will provide details of the distinctive research methodology and methods, it is pertinent here to note that from the outset the team shared in the development of all dimensions of the research design. Fijian colleagues, including academics, teacher educators, and practising teachers (see Appendix 1), then led the local fieldwork, and the UK partners led in connecting the joint analysis to the international theoretical literature and to the contemporary challenges generated by what we see as increasingly powerful drivers of global education policy transfer. The overall storyline for this article and a division of labour in writing it across all of the team were agreed at a workshop at USP. Members of the team from each of the partners then presented a first version of the paper jointly at the BAICE 2016 conference and then had a further workshop to plan revisions based on conference feedback. Parenthetically, the use 
of project funding to ensure space for collaborative writing appears to offer important advantages in moving towards shared ownership of authorship.

However, although the research engages with the global values, strategies and challenges faced in improving educational quality, and the opportunities to support teacher professional development in the pursuit of this goal, we argue that this has to be understood with reference to a further analysis of the distinctive socio-cultural dynamics as experienced in the South Pacific and Fijian contexts (see the more generic arguments developed in Crossley and Watson, 2003). Thus, our initial research question was developed within a socio-cultural framework to examine:

How are issues of teacher becoming, being and belonging understood in Fiji by different stakeholders ... and what implications does this have for the drive to improve the quality of teaching and learning?

This further suggested that we must also pay detailed attention to: the nature of teachers' work and lives; how this is shaped by a diversity of local and professional cultures; gender discourses and practices; the ways in which change relates to broader educational system dynamics; the nature of teacher education; and finally, how this all interacts with the wider political economy of development and global policy trajectories. As the project developed, it became increasingly clear that tension between multiple versions of local and global education were at the heart of the ongoing debate about quality learning and teaching in Fiji. This also strengthened the rational for our engagement with postcolonial perspectives and sensitivities that have pertinent strengths in revealing the political dynamics and power differentials at play in educational reform.

In what follows, we firstly examine some of the most pertinent theoretical literature that can be brought to bear on these issues, and provide a brief analysis of the changing, and widely contested, Fijian education policy context (Thaman, 2004; Koya, 2015). This is followed by a discussion of the innovative methodological positioning that we have developed in blending Pacific and Western research approaches. We then present the findings from our original Fijian fieldwork data and analysis around four core themes: understanding the nature and quality of Fijian education; the challenges of teachers' work and lives; policy priorities for the successful implementation of reform; and implications for policy transfer and the interplay of global and local values in future practice. We conclude by examining the implications for the related theoretical literature, and by considering how this Fijian, small state, research may contribute to enhanced understanding of the role of the teacher in programmes designed to improve the quality of sustainable and contextually relevant teaching and learning worldwide.

\section{Theoretical Perspectives and their Implications}

A current and growing dimension of the international debate about post-2015 education and development is the extent to which a focus on global goals and the results of international surveys, league tables and trends can lead to overly simplistic education policy transfer that underestimates the significance of local contextual factors and thereby reduces the chances of successful implementation in practice. In the light of this, our theoretical approach to educational reform is grounded in a resurgent body of work on policy transfer and borrowing in education (e.g., Steiner-Khamsi and Waldow, 2012; Auld 
and Morris, 2014), and our own core argument that emphasises how "context matters" more than many policy makers and researchers realise (Crossley, 2010). As already noted, this is particularly significant in the Pacific region where PICs have suffered an almost total marginalisation from international policy debates.

On a more specific level we go beyond the results of the PISA surveys (cf. OECD, 2010) and their implications for appropriate pedagogies, learning technologies and teaching standards, to look for local possibilities for improvement in teaching and learning quality. This is not to oppose arguments that teachers' performance could and should improve, but to both note the problematic nature of external agendas of performativity and to insist that improved performance must build on what is feasible in light of the structural constraints of teachers' work and lives (Day and Gu, 2010; Buckler, 2011 and 2015).

Indeed, there is also an increasingly visible literature in developing country contexts that shows how internationally inspired or driven teacher education initiatives often fail due to their misarticulation with the realities of the schools, educational systems and societies in which teachers work and live (e.g., Saito, Tsukui and Tanaka, 2008; Schweisfurth, 2011). Moreover, in the Pacific Islands, educational reform has long tended to neglect the views of practising teachers, contributing to a disconnection between policies and implementation, and undermining sustainable educational reform at the classroom level (Crossley and Vulliamy, 1984; Thaman, 2004, 2007 and 2008). This is behind our interest in local imaginaries of what defines the "ideal" teacher (Koya, 2012).

The multi-level research reported here thus considers the micro-level, lived experience of practitioners and meso-level concerns dealing with educational structures - alongside an understanding of the macro-level effects of policy transfer and uneven global development. These macro-level effects include the impact and politics of aid dominance (McGrath and Badroodien, 2006; Cassity, 2008; Ruru, 2010), and the effects of globalisation and postcoloniality (Thaman, 2004; Crossley and Tikly, 2004; Nabobo-Baba, 2006a and 2008), in addition to previously noted work on policy borrowing and uncritical international policy transfer (Crossley and Watson, 2003; McGrath, 2010; Crossley and Watson, 2011; Tuinamuana, 2002 and 2007). Finally, locating this form of analysis within the context of the Pacific Islands, and the wider experience of SIDS, further strengthens the potential and originality of this contribution to the existing international literature that has tended to be concentrated on research in larger countries.

\section{The Changing Fijian Education Policy Context}

Fiji is a small Pacific island nation comprised of over 300 islands with a population of just under a million people, sitting at 837,271 in 2007 (Fiji Bureau of Statistics, 2016). The island nation was a colony of Great Britain for almost a hundred years, gaining its independence in 1970. During the colonial era, Fiji adopted the British system of education and while independence promised self-direction in education, most of the colonial policies, practices and structures remained in place for many years. In the early post-independent system, an arrangement was established which saw the use of New Zealand curriculum content, textbooks and national examinations. This arrangement ceased in the 1990s when locally developed national curriculum and examinations were introduced in Fiji schools. 
Education is administered through a centralised approach and national curriculum decisionmaking is conducted at the Ministry of Education in Suva, governed by the 1978 Education Act. The Act was reviewed in 2013 and is pending a decision on next steps from the Solicitor General's Office. Four Education Commissions have been convened in Fiji with three conducted during colonial times in 1909, 1926, 1969 and one most recently, in 2000. The 2000 Education Report found that many of the challenges identified by the previous commission in 1969, remained core concerns. These included issues of access and equity, the need for curriculum reform, improved teacher supply, the quality of teaching and teachers, and a perceived need for a move towards student-centred pedagogies (Koya, 2015, p.23).

Since 2000 there have been a series of policy initiatives that have responded to concerns that the Act, and linked practices, are in need of revision. These include the Education Commission Report (Fiji, Ministry of Education, 2000), the Systems-based Curriculum Mapping Exercise (ongoing since 2003) and the Suva Declaration (Fiji, Ministry of Education, 2005). From 2007, these initiatives fed into the attempt to develop a National Curriculum Framework (NCF).

It would be another six years before the NCF was endorsed in 2013 after community consultations. These consultations were established with the understanding that core curriculum concerns needed to be addressed systematically. The main issues of concern included a content-heavy, repetitious and poorly sequenced curriculum; efforts to break the hold of examinations on learning; labour market needs; and, the cultural relevance of content and pedagogies. The vision of education expressed in the NCF is:

To provide a holistic, inclusive, responsive and empowering education system that enables all children to realize their full potential, appreciate fully their inheritance, take pride in their national and cultural identity and contribute fully to sustainable national development (Fiji, Ministry of Education, Heritage and Arts, 2013, p. 1).

The underlying guiding principles informing this vision are social constructivism, influenced by the 1996 UNESCO International Commission on Education for the Twenty-first Century (the Delors' Report) (UNESCO, 1996). Under the principle of social constructivism, the NCF advocates for active learning, learning as a social process and students as agents of their own learning. From the Delors' Report, it draws on the concept of four Pillars of Education: learning to know, to do, to be and to live together. At the same time, under the principle of cultural influences, it promotes a culturally democratic curriculum, culturally inclusive pedagogies and learning about inclusivity and diversity (ibid., pp. 12-16).

The Curriculum Advisory Services Unit at the Ministry of Education then launched a curriculum review under the NCF and headway was made towards developing new curricula along these lines over the 2013-2014 period. However, in 2014, national elections were held and the new government's position on the NCF has remained unclear since then. Although the NCF is still officially advocated as the primary guiding policy framework by Ministry officials, many policy initiatives and curriculum reforms post-2014 appear to be misaligned with the general direction, specific objectives and educational outcomes articulated in the NCF, and the tensions generated by this were clearly visible at all levels throughout our research period. 
In October 2015, a policy statement was released clustering three main priority areas for future action (Ministry of Education, 2015). These consisted of curriculum content review and development; teacher delivery; and infrastructure. This statement did not make mention of the NCF at all. It did, instead, outline plans to conduct what is called a comprehensive curriculum review "to bring it to par with the curriculum of schools in Australia, New Zealand and India". This was to be conducted in 2016 but has been delayed due to the devastating effects of Tropical Cyclone Winston. The plan also outlined a commitment to ensuring that teachers abide by teaching the whole of the existing syllabi; a reinstatement of national examinations, which had only recently been removed; and, the exclusion of teachers from setting examinations and any moderation roles.

The October 2015 plans also contained a strong focus on teachers under the two headings of teacher training and recruitment and teacher competencies, assessment and leadership. Under the former, the Ministry stated its intention to continue dialogue with teacher education providers with a view to adopt a common education curriculum by 2016 to ensure that they "will learn the same skills and have the same teacher training and subject delivery skills" (p.2). It is planned that teacher numbers will be increased and more specialist teachers introduced into upper primary years. Where there are surplus applicants for teacher education places, it is proposed that selection will be on school grade point averages.

Furthermore, all Ministry communication in the local media and discussions with national teacher education providers at that time suggested dissatisfaction with teacher performance, and the October 2015 plan emphasised Ministry initiatives to address this. Specific strategies included a Basic English Proficiency test for all teachers in Fiji "to ensure competency of teachers in both oral and written English" (MoE, 2015). Moreover, teachers would now be subject to assessment by students and their immediate supervisor alongside the analysis of the outcome of external examination results on an individual teacher basis. Furthermore, counselling has been identified as a core skill required by all teachers and while the Ministry has confirmed it is providing counselling services to students through the establishment of full-time counsellors at the nine district offices, there is emphasis on "equipping every teacher with basic counselling skills" (p.3). Finally, the temporary appointment of roving Head Teachers and Principals will see experienced and proven school heads relocated to assist in the development of "underperforming schools for a short period while mentoring the new appointee" (ibid.).

The influence of current international trends, including the results and influence of the global PISA surveys, parallels with recent policy initiatives prioritised in the UK, the centrality of learning outcomes, and the assumed benefits of high stakes testing and of enhanced teacher accountability can be clearly seen in these initiatives. This poses challenges to the learner-centred philosophy and professional autonomy that characterises the NCF and is widely supported by practising teachers and teacher educators. This is the changing and highly contested policy context within which the Fijian study was carried out

\section{Research Methodology and Methods}

As fieldwork began, the initial research question was refined to focus upon three main issues: 1 . stakeholder perspectives of the nature and quality of teaching in Fijian schools; 2. their understanding of the challenges being faced in practice; and 3. priorities for attention 
if the quality of education is to be improved? Particular attention was also given to accessing and understanding practitioner perspectives as detailed below.

\section{Rationale for Blending and Mixing Pacific and Western Approaches}

Given the focus of the study a largely qualitative methodological approach was emphasised. This was informed by work on postcolonial methodologies, including that by indigenous Pacific scholars such as Linda Tuhiwai Smith (1999). This helps to reveal power differentials while challenging Western hegemony in education policy and practice. Postcolonial sensitivities thus helped to inspire our mixing of Western and Pacific fieldwork methods, including questionnaires, talanga (consensus building through structured stakeholder consultation) and talanoa (dialogic participant-researcher conversations). Postcolonial perspectives also underpinned the insider/outsider partnership strategy (McNess et. al. 2015), and this again helped to shape the blending of Pacific and Western methodologies in strengthening the robustness of the data through methodological triangulation, and engaging more closely with local stakeholders, in ways that they would find more comfortable and culturally familiar with the visible acknowledgement and application of Pacific values, traditions and practices.

\section{Key Research Methods, Samples and Research Sites}

The sample of participants comprised primary and secondary teachers from the three main centres in Fiji: Suva, Labasa and Lautoka. Teacher trainees and teacher educators at The University of the South Pacific, the Fiji National University and the University of Fiji were also sampled, as well as representatives from the Ministry of Education, teachers' unions and the Fiji Teachers Registration Board. The fieldwork was carried out between May and December 2015.

Questionnaires were distributed to 75 participants, comprising 15 primary and 15 secondary teachers; 15 primary teacher trainees and 15 secondary teacher trainees; and 15 teacher educators. 69 questionnaires were received back giving a high response rate. In line with the qualitative methodology, the instrument emphasised personal narratives and prioritised open ended questions. The questionnaires were designed to elicit information about general attitudes, beliefs and worldviews of the three groups in direct relation to the three main parts of the core research question: 1 . the nature and quality of teaching and learning, 2. challenges faced in practice and 3. priorities for attention relating to the quality of education in the Fiji context.

Talanga sessions were conducted at The University of the South Pacific (USP), University of Fiji and Fiji National University (FNU). The locations selected for these sessions were Suva, Labasa and Lautoka. A talanga session was organised for six teachers at each location, and a separate session for at least three teacher educators at each participating university. Talanoa were conducted with two primary and two secondary teachers at each site, and three teacher educators at each university. Talanoa were also organised with Ministry of Education officers. The total number of talanoa sessions numbered 22.

Talanga played a probing role in moving beyond the questionnaire data, and as a research method may be likened to focus group discussions. In this study talanga sessions were 
arranged with groups of five to eight participants. While there is no fixed agreed number of participants in a talanga, it is generally understood that smaller groups make for more meaningful engagement with each participant contributing to the conversation. Koya (2015, p.145) explains the difference between talanoa and talanga:

Tâlanga provides more structure to the information gathering process than Talanoa, in that it has a designated setting - a planned time, setting and environment, whereas Talanoa may take place anywhere at any time and may involve the free movement of participants in and out of the discussion in a flexibility that Tâlanga does not accord.

In the context of this study, group sessions were pre-arranged and the sessions were guided by a set of predetermined questions. Field research focal points were identified at the three Universities to allow for non-obtrusive data collection particularly of student teachers and teacher educators.

Talanoa sessions also probed further in to the key issues to generate a deeper level of understanding. Talanoa is considered a contextually relevant cultural approach to storying or sharing of personal narratives. Talanoa is generally understood and utilised as a research method by many Pacific scholars (e.g., Vaioleti, 2006; Nabobo-Babu, 2006b; Johansson-Fua, 2008; 'Otunuku, 2011; Naisilisili, 2012; Fairbairn-Dunlop and Coxon, 2014; Koya, 2015), and is most similar to the semi-structured interview. It is described as an informal conversation in which "knowledge is socially constructed" (Johannson-Fua, 2008, p1). While in everyday life, talanoa may take the form of a casual and uni-directional conversation about anything and everything; in research it is more structured. In this study, a set of guiding questions were developed for the talanoa/interview sessions. These provided focus for the field researcher when and if the discussion deviated away from the primary focus of the study. While the cultural fit of these innovative indigenous methods helped the research team to engage more closely with local Fijian teachers in ways they could understand, consistent with cultural expectations and community practices, status and power differences between the research team and the research participants often remained significant. These limitations, and their potential impact on the trustworthiness of participant feedback, thus warranted close consideration by the team as we processed and examined the findings.

Data from the questionnaires, talanga and talanoa sessions were manually coded and analysed searching for emerging patterns in the results obtained. Researcher fieldnotes comprising observations and general feedback on the talanga and talanoa were also documented. These findings were written up in the form of detailed texts and narratives for team reading and review, leading to the identification of key themes. These emergent themes were then reconsidered in the light of the three dimensions of the research question, and from this our findings on the nature and quality of teachers and teaching in Fiji, and on the key challenges and priorities for attention, were identified as reported below.

\section{Research Findings: Implications for Future Policy and Practice}

\section{The Nature and Quality of Fijian Teachers and Teaching}

In considering the nature and quality of teachers and teaching, particular attention was given to perceptions of the characteristics of the "ideal Fijian teacher" (Koya, 2012), 
implicitly stressing the contextualised nature of quality. This was a highly sensitive issue given the significant changes in direction that were being introduced by the Ministry during the fieldwork period. In what follows, accounts portraying the qualities of the ideal teacher are contrasted with perceptions of the current quality of teaching and the teaching profession. Overall, the research identified widespread consensus amongst sampled teachers, student teachers and teacher educators regarding quality education and the attributes of the ideal Fijian teacher. Eight attributes emerged, although there is inevitable overlap between them.

First, the ideal teacher was seen to be guided by the expectations of national policies, standards and curricula. Student teachers in particular stressed that teachers should meet Ministry rules and regulations; whilst qualified teachers emphasised working hard to meet Ministry deadlines.

Teachers work is guided by Ministry requirements and they should be aware of these expectations (Male secondary student teacher).

We work hard to meet deadlines and complete all tasks on time (Female secondary teacher).

The teacher educators put an additional emphasis on commitment to the school mission and culture. Strikingly, there was a strong emphasis in applying the philosophy of the NCF. Given the uncertainty about the NCF's future and the continuity of overall national educational philosophy, it will be interesting to see whether this reflects some degree of distance between Ministry and educator views about the future direction of Fijian education. In this light, there appeared also to be some sense amongst teachers that there might be two views of the ideal Fijian teacher: one which privileged work towards examination results alone, and another that gave more weight to lifelong learning and wider notions of quality education and professional identity formation. The latter can be seen strongly in several of the other characteristics. A male secondary teacher clarified what he saw being valued from official perspectives:

At the moment, students' performance is more valued as it reflects teachers' contribution to teaching. This is circulated to Administrators and communicated to teachers.

Second, the ideal teacher was seen to have a strong sense of identity guided by professional ethics and moral standards. However, there were interesting variations across stakeholder groups. Student teachers tended to stress an awareness of the identity of the teacher as well-prepared, hard-working and focused on the academic success of students. Thus, one female secondary student teacher argued that

[the ideal teacher] assumes ownership for classroom and students' success, and is responsive to students' needs, and maintains professionalism always.

However, teachers and teacher educators put more emphasis on teacher collegiality; on holistic child development; and on building relationships of trust. As one female primary teacher put it:

[the ideal teacher] develops healthy relationships and is honest, trustworthy and accountable. 
Whether this difference between beginning teachers and more senior colleagues is anything more than an artefact of our data collection is impossible to know. However, if it is more systematic, it could point to an interesting spread of more narrow performative accounts.

Third, the ideal teacher was believed to have a passion for teaching and facilitating student learning. Student teachers did agree with this but had a more restricted view, as expressed in the previous student quotation, and perhaps reflecting their limited professional experience. Teachers developed this notion further, to include the creation of a positive learning environment; motivation and facilitation of learning; and a stress on helping all students to achieve both system and personal goals. Much of this was echoed by teacher educators, who also emphasised an ability to respond positively to constructive criticism; a focus on planning and resourcefulness; a commitment to accountability; and leadership qualities. A female secondary teacher explained that the ideal teacher was "One who nurtures and guides a child to value his religion, his community and family and most importantly his personal goals." A male counterpart argued that that the ideal teacher "has a positive attitude and is always on time, prepare his lesson plans and is honest, passionate and treats everyone equally." Thus, again, a broad sense of humanistic, collegial practice is at least espoused.

Fourth, the ideal teacher was seen to be cognisant of cultural, social and learning contexts in the classroom in order to facilitate student learning. Student teachers particularly highlighted the importance of emotional intelligence; whilst all had a sense of the importance of cultural values and Fiji's multicultural nature. Sensitivity to learner diversity was also valued, with teacher educators introducing the importance of using this diversity to enhance the learning experience.

A teacher who is creative and innovative enough to take up the challenge of teaching all students irrespective of race and ability for improvement and progress (Female primary teacher).

A teacher who dedicates his/her time for the children he/she teaches, who honestly does the work with high level of integrity (Female secondary teacher)

Fifth, the ideal teacher is well versed with subject content knowledge. Indeed, this was so universally accepted that it saw little elaboration by the participants.

Teachers should be well prepared and well-versed with the syllabus (Male teacher educator)

[She or he] knows the subject content and applies what has been learnt in the classroom to ensure that all students are given the same opportunity to do well in their studies (Female secondary student teacher)

Sixth, the ideal teacher was seen to be up to date with pedagogical developments, innovative and able to apply a wide range of teaching strategies to enhance student learning. For all participants, having a wide repertoire of pedagogical tools, which reflected current professional thinking, was seen as essential.

She or he must be well-versed with a range of teaching methods (Female secondary teacher) 
Teachers need to be creative in their approaches to create an interest in learning and should apply a wide range of approaches in their teaching (Female teacher educator)

With these last two items, it appears that there is a language of improvement that appears in keeping with international discourses, although the localisation of this at the level of detail can also be seen from some of the earlier themes.

Seventh, the ideal teacher was seen to prioritise student learning needs and safety. Teacher educators particularly emphasised the holistic development of the child. Teachers, perhaps cognisant of the current policy debate about teachers as counsellors, stressed the importance of this role and the need to understand, value and nurture students. Indeed, they saw the welfare of students as a major priority

Teachers should be passionate about teaching and their students. All students have dreams. Each is unique and teachers build relationships with them (Female secondary teacher)

A Teacher who cares for the children. Does things or uses strategies to uplift the standard of the students' learning, values time and adjusts well to situations (Male primary teacher).

The eighth characteristic acknowledged a value for education beyond the schooling experience. Teachers and student teachers emphasised how teaching should be a human encounter that extends beyond content knowledge to develop global citizens. In so doing they mirrored some of the language of the NCF and reflected the spirit of related international educational discourse with many using terms such as "holistic learning experiences", "the whole child", "responsive to students' needs", "builds relationships" and "safe learning environments" for example.

Across these eight domains, there is much acceptance of the performance and accountability elements of education quality and teaching: that teachers should be hardworking, focused on learning outcomes and examination results, and responsive to the bureaucratic requirements of the system. This seemed to be most strongly voiced by novice teachers. However, there also appears to be a stronger sense of the importance of a lifelong and lifewide view of education expressed by more experienced practitioners, and of quality in the form of equity and embeddedness in culture and community. Most accounts seemed able to articulate some accommodation between these two strands. However, there were significant voices that pointed to concerns about the increasing visibility and influence of a policy shift towards the former accountability- and examination-led culture and away from the latter and broader conceptions of quality.

Most strikingly, in spite of the emphasis in much of the discussion of the ideal teacher about notions of learner-centred education, of the teacher as facilitator and the primacy of the learning, it was widely believed that teacher-centredness had long predominated in practice in Fijian classrooms. Two examples of this perception from the fieldwork data serve an illustrative purpose:

It is the teacher-centred approach that is used as most teachers worry to cover the syllabi then to make children understand what they are teaching (Female primary teacher) 
Often it is the traditional approach because most of them follow the text book. Whatever is there in the text book they just try to teach directly to the students. Student involvement is limited (Male secondary teacher)

Whilst some argued that the Ministry was responsible for this, and saw it as once again trying to heighten teacher-centredness through emergent policy trajectories, it is implausible that very recent policy directives alone are at the root of what are more likely to be deep-seated cultures of teaching and learning.

What is apparent from the data overall is that there is deep concern about the future direction of both teachers' work and teaching. This appears to be coupled with important questions about the future for a distinctive Fijian philosophy of teaching and learning.

\section{The Challenges of Teachers' Work and Lives: Practitioner Perspectives}

We have argued above that the possibilities for improved learning are grounded in an important way in their notions of the ideal teacher. These, in turn, are influenced by the lived realities of teachers, which both constrain and facilitate their improvement in performance. Looking across the findings from the questionnaires and the talanga and talanoa sessions held with teachers, teacher trainees and teacher educators, a sense of constraints, or challenges, was far more pervasive than opportunities. As with many of their counterparts internationally, Fijian teachers largely perceive their job as getting harder, not easier. Perceptions of the main challenges faced by practising teachers can be considered in six categories. These consist of challenges related to 1 . the Ministry of Education level; 2. the school level; 3 . the teacher; 4 . the curriculum; 5 . students and 6 . the community.

\section{The Ministry of Education Level}

The most prominent challenge perceived by all stakeholders at this level is the rapid pace of educational reform, repeated shifts relating to policy, curriculum and assessment, and associated changes in regulations and procedures. Talanga sessions thus reveal significant teacher stress and frustration with what are perceived to be overwhelming and uncoordinated curriculum changes being rolled out. Teachers and trainees reported a sense of what was described as reform lethargy in the face of the frequency of Ministerial circulars requiring rapid change. As one male secondary school teacher reported, "We are like machines. We don't get to think anymore". Practising teachers expressed general disappointment at the lack of teacher consultation in the numerous changes being implemented, and concern at the pace and number of new initiatives. They said they were confused about whether to follow the NCF principles when implementing the new initiatives particularly in regard to assessment and examinations. Teachers spent a lot of time emphasising their disappointment at the swift return to external examinations, saying that they and their students had just become familiarised with and confident in the internal assessment processes. They emphasised the importance of assessment for learning (AfL), as stated in the NCF, which was now increasingly sidelined by the shift to the assessment of learning (AoL) via examinations.

Perhaps most pointedly, in the talanga sessions the teachers shared the view that the current fast paced, multi-faceted reform across the board and on numerous levels was the 
biggest risk to compromising an already cluttered system. Talanga participants also argued that policy reform was partly driven by international trends and the national desire to remain comparable with other nations without due contextualisation taking place.

\section{The School Level}

At the school level the most prominent challenges that were reported related to working in rural and remote locations. This was combined with the lack of resources and facilities, poor quality textbooks, limited access to technology and low level of support from school administrations and school boards. In the talanoa sessions teachers expressed a desire for improved school leadership, and better leadership training, to ensure quality education. As one male secondary teacher reflected:

There is a leadership crisis and people without appropriate leadership qualities got promoted during the 2010 regularisation process e.g. Maths/ Basic Science graduate getting confirmed HoD post of PEMAC (Physical Education, Music and Arts and Crafts). With the confirmed post they easily move up to administrative level without the appropriate qualification, training and skills and the school staffs suffer.

\section{The Teacher}

Teacher-related challenges highlighted perceptions of heavy workloads related to studentteacher ratios, composite classes, increased paperwork and extra curricula responsibilities. Teacher stress was identified in particular relation to increased formal accountability, closer monitoring by the $\mathrm{MoE}$, reduced starting salaries for pre-service teachers and limited promotion opportunities. Time constraints were highlighted as a major challenge by teachers when trying to fit what they perceived as overloaded curriculum content into the school year. In talanga sessions many teachers reported that it was not a good time to be a teacher in Fiji, particularly if you are responsible for an examination form, as evening and Saturday classes meant even less time for family and other responsibilities. Of particular significance to most teachers were challenges generated by their responsibility for examination results, and the potential blame associated with poor student performance.

There is a lot of stress with down flow from MOE and very high expectation from MOE in a very short timeframe. Family time is greatly affected as work needs to be completed at home (Male secondary teacher)

\section{The Curriculum}

Primary education was widely perceived to be reverting to a content-driven curriculum emphasising examination outcomes and challenging the more holistic philosophy valued by the profession. As one female primary school teacher reported:

A Fijian teacher works hard to meet due dates, to meet submission of official records that in most cases or times, children's learning times are used to complete records. A Fijian teacher teaches from the textbook supplied by 
the MoE and using the exam papers supplied to produce good results, rather

than their life-long learning.

This is supported by the questionnaires where the majority of teachers agreed that the focus of teaching is increasingly on the transmission of facts for rote learning and that many teachers were not encouraging active learning. The quality of the new curriculum was also emphasised as a challenge with teachers arguing that some of the new textbooks were of inferior quality and contained many errors. They also highlighted problems with sequencing of the curriculum, with some content placed at very high levels beyond students' prior learning and knowledge.

\section{Students}

Student-related challenges that were perceived to be most significant emphasised those stemming from diverse student learning needs and differential ability, student attendance, poor attitudes towards learning and behaviour in addition to weak performance in tests and examinations. Talanoa findings thus reveal a fear about the importance of the new student assessment process for the career prospects of teachers, the idea that students may use this as leverage to get their own way, and a general concern that teachers wishing to make a difference may become frustrated, resulting in the loss of higher quality teachers and a subsequent decline in the quality of teaching and learning.

One teacher I know complained that her class did not want to take Science class and asked for a free period for sports. When she said no, a student said they would give her a bad report in the assessment sheet. (Female secondary teacher)

\section{Community}

A final set of challenges faced by Fijian teachers were seen to relate to the wider community, to cultural and language barriers and a lack of parental support. Questionnaire findings thus revealed that the majority of teachers surveyed believe they are not well respected in society and they need more support in terms of resources, guidelines and salaries. Similarly, teacher educators perceived a decline in societal respect for teachers and a lack of appreciation of them as professionals. The talanoa sessions suggested that much public discourse appears to be finger pointing at the teaching workforce for the failings of the education system, and in particular for low literacy and numeracy rates and poor examination results. Two extracts are illustrative of the wider tone:

Teachers are not respected like before. Now teachers are blamed for students not doing well in exams. (Male secondary teacher)

We are expected to be like machines. (Female secondary teacher)

Analysis of the above findings points to a number of policy priorities from the perspectives of practitioner stakeholders. These were presented to the Fiji Ministry of Education during 2016 in the form of meetings and a concise Education Policy Briefing paper (USP, 2016). Key issues emphasised the need for more realistically paced and consistent reform, clarification of the place of the NCF, critical reflection on the intensification of high stakes examinations, and implications for the revision of teacher education programmes nationwide. Further 
details are available elsewhere (see www smallstates.net), but here we move beyond the level of policy impact to focus on the related theoretical issues and implications.

\section{Research Findings: Implications for Theory}

The Fijian case reinforces our existing arguments that "context matters" more than is often acknowledged, and illustrates the complexity of this in a small island development state setting. Fiji's relative success in meeting the EFA agenda and its smallness and remoteness from the major centres of international education policymaking make it a relatively distinctive and challenging case in terms of the most familiar arguments about aid dependence. Whilst Fijian education does not have huge internal resources, and the devastating impact of Tropical Cyclone Winston during our fieldwork period led to a major campaign of seeking external financial assistance, it is often not through aid projects and attached conditionalities that international influences make inroads into Fijian policy and practice. Rather, we can see evidence of the influence of international thinking much more clearly at the discursive level. Most strikingly, our research demonstrates how educational reforms since 2013 have drawn strongly from international discourses on educational performativity and teacher-blaming, including repeated use of the language of international benchmarking. That the identified comparator countries are India, Australia and New Zealand points to the particular postcolonial nature of Fiji where these three countries loom larger in the Fijian national imaginary than do the usual set of "PISA stars" (see Crossley, Hancock and Sprague, 2015).

It is easy to read the disagreement between the practitioner and Ministry imaginaries of the quality teacher and quality education as one of the local versus the global. However, there are at least two disruptions to this reading. Both centre on the nature of a Fijian conception of learner-centredness. On the one hand, as indicated above, the intellectual referencing for this lies with UNESCO and the Delors Report. So what does this mean for notions of cultural fit? Could it be that while there is a genuine Fijian belief in the benefits of learnercentredness it is more convincing to deploy UNESCO rather than local voices as the legitimising authority in this regard? On the other hand, the Fijian practitioner claim to value learner-centredness appears to be more powerful than the evidence of this in widespread practice. Could this mean that learner-centredness may also act as a rhetorical device with which to resist increased accountability and a culture of performativity?

Whilst classroom practices might be rather less learner-centred than the rhetoric suggests, the voices of teachers, student teachers and teacher educators all point to a discourse that is resistant to increased performativity and the credentialised models of education that are spreading under the influence of neoliberal globalisation. Rather, the practitioners in our study appear to be sure that education is about much more than this. Whatever the mix of international and indigenous values may be in this humanistic education vision, it is certainly an important resource for resistance against more illiberal trends.

By focusing on what educators think about their role we can open up a critical and revealing conversation with the performative discourse. This helps to challenge the labelling of resistance to performativity as the biased views of "vested interest" and/or laziness. Rather, it makes it possible to acknowledge how practising teachers, though inevitably fallible, are committed to educational quality, but to a version of this that is far richer and more complex than that promoted by tests and performance measures alone. The account 
presented here of a Fijian notion of the ideal teacher and quality education is rooted in the very particular interplay of Fijian, broader Pacific Island, Indian and global cultures that characterised the colonial and other encounters at a specific moment in time. It does, however, offer much for those committed to real qualitative improvements in practice. In the light of this, we argue that similar research is important in other contexts to understand local imaginaries of educational quality that can (and should) then inform national education policy debates.

\section{Conclusions}

This research represents a collaborative effort that has brought together an international team of researchers interested in the quality of education and the implications of this for teachers, teaching and teacher education in Fiji. It is hoped that the findings will help to inform debates in Fiji, and beyond about the quality of education in realistically grounded ways that may contribute to future improvements in teaching and teacher education policy and practice.

More broadly, this Pacific experience both supports and challenges elements of the related international literature in ways that could make a helpful contribution to theory and to ongoing global deliberations and success in meeting the UN sustainable development goals. Indeed, as argued at the outset of this article, there is much that the international community can learn from the experience of SIDS, including Fiji and other PICs. Perhaps most importantly, the significance of context in education policy formulation, and the dilemmas of simplistic international education policy transfer are heightened and made more clearly visible by examining the case of small states, as are the tensions between international education priorities and agendas and local contextual realities (Crossley, 2010). This is, therefore, revealing and helpful research for all systems and agencies involved in educational reform, North and South, rich and poor, in times characterised by intensified globalisation.

The importance of locally grounded, practitioner perspectives on educational reform is also well demonstrated here, with the Fiji findings doing much to support existing research that highlights the importance of understanding the practical realities of teachers lives and work in context, if the chances of successfully implemented educational reform are to be increased. In times when the influence of international surveys of student achievement and related league tables is seen to be determining policy trajectories worldwide, this has increasingly important cultural and political implications (Ozga, 2012; Meyer and Benavot, 2013). Fijian education, we have shown, is prioritising qualitative improvement, but in doing this there are significant tensions between notions of learner-centred and culture sensitive quality that are embodied in the NCF, and the more recent resurgence of a high stakes, content and examination-driven culture inspired by the influence of global surveys and dominant, neoliberal international policy trends. The negative impact on teacher morale and commitment of this move away from policies that are perceived to be more consistent with Pacific values, is further compounded by what are reported to be repeated, inconsistent and ever more demanding pressures for change and increased accountability. Returning to the framing of our overall analysis, there is considerable evidence throughout our findings to suggest that the tensions faced by practitioners at all levels in Fijian education could reflect the emergent resistance of the professional community to the 
hegemony of the international accountability movement and the intrusion of a performativity culture into Pacific contexts where they sit uncomfortably with collective community values and traditions.

In terms of research methodology, our international partnership has also been informed by postcolonial sensitivities and innovative Pacific approaches as we have sought to capitalise on the strengths of a combination of insider and outsider perspectives (McNess, Arthur and Crossley, 2015). Our research thus challenges many of the assumptions that underpin the search for global "best practice" in education, recognising the contextual dimension of quality in education and the implications of this for pedagogy, teacher education and the creative mobilisation of both global and local values if sustainable improvements to the quality of education are to be achieved.

\section{References}

Auld, E. and Morris, P., 2014. Comparative education, the 'new paradigm' and policy borrowing: Constructing new knowledge for educational reform. Comparative Education. 50, 2, 129- 155.

Buckler, A., 2011. Reconsidering the evidence base, considering the rural: Aiming for a better understanding of the education and training needs of Sub-Saharan African teachers. International Journal of Educational Development 31, 3, 244-250.

Buckler, A., 2015. Quality Teaching and the Capability Approach. Routledge, Abingdon.

Cassity, E., 2008. Cast the net a little wider: Australian aid in the South Pacific. International Journal of Educational Development 28, 3, 246-258.

Crossley, M., 2010. Context matters in educational research and international development: Learning from the small states experience. Prospects 40, 4, 421-429.

Crossley, M., 2014. Global league tables, big data and the international transfer of educational research modalities. Comparative Education 50, 1, 15-26.

Crossley, M., Bray, M., Packer, S., with Atchoarena, D., Colin, M., Martin, M. and Sprague, T., 2011. Education in Small States: Policies and Priorities. Commonwealth Secretariat, London.

Crossley, M., Hancock, G. and Sprague, T. (Eds.), 2015. Education in Australia, New Zealand and the Pacific. Bloomsbury, London.

Crossley, M. and Vulliamy, G., 1984. Case-study research methods and comparative education. Comparative Education 20, 2, 193-207.

Crossley, M. and Watson, K., 2003. Comparative and International Research in Education: Globalisation, Context and Difference, Routledge Falmer, London.

Crossley, M. and Watson, K., 2011. Comparative and international education: policy transfer, context sensitivity and professional development. In Furlong, J., and Lawn, M. (Eds.), Disciplines of Education: Their Role in the Future of Education Research. Routledge, Abingdon.

Day, C and Gu, Q., 2010. The New Lives of Teachers. Routledge, Abingdon.

Fairbairn-Dunlop, P. and Coxon, E. (Eds.) 2014. Talanoa. Building a Pasifika Research Culture. Dunmore Publishing Ltd, Auckland. 
Fiji Bureau of Statistics, 2016. Population Census and Surveys. http://www.statsfiji.gov.fi/statistics/population-censuses-and-surveys

Fiji Ministry of Education, 2000. Learning Together: Directions for Education in the Fiji Islands, Education Commission Report. Government Printers, Suva.

Fiji Ministry of Education, 2005. Suva Declaration. Government Printers, Suva.

Johansson-Fua, S., 2008. Research and the Pacific teacher: an introduction to school-based research -introduction to research approaches. Unpublished paper prepared for the Tonga Institute of Education, Research Training, Nuku'alofa, Tonga.

Koya, C., 2012. Rethinking Pacific teacher standards: Reflections on a value-theory approach to conceptualizing the 'ideal' Pacific teacher. School of Education Talanga Seminar Series, USP, Suva, March.

Koya, C., 2015. Pedagogical Practices in Fiji Schools. In E. Hau-Fai Law and U. Miura (Eds.), Transforming Teaching and Learning in Asia and the Pacific: Case Studies from Seven Countries, (pp.22-43). UNESCO, Paris.

Lingam, G., Ratruri, S. and Finau, K., 2015. Pacific Island Countries: Improving educational $r$ each with information and communications technologies. In Crossley, M., Hancock, G. and Sprague, T. (Eds.), Education in Australia, New Zealand and the Pacific. Bloomsbury, London.

Mayer, H. D., and A. Benavot (Eds.), 2013. PISA, Power and Policy. The Emergence of Global Educational Governance. Symposium, Oxford.

McGrath, S., 2010. Beyond aid effectiveness: The development of the South African further education and training college sector, 1994-2009. International Journal of Educational Development 30, 5, 525-534.

McGrath, S. and Badroodien, A., 2006. International influences on the evolution of skills development in South Africa. International Journal of Educational Development, 26, 5, 483494.

McNess, E., Arthur, L. and Crossley, M., 2015. 'Ethnographic dazzle' and the construction of the 'Other': revisiting dimensions of insider and outsider research for international and comparative education. Compare, 45, 2, 295-316.

McKinsey, 2007. How the world's best performing school systems come out on top. http://mckinseyonsociety.com/downloads/reports/Education/Worlds School Systems Fina I.pdf Accessed on 16/07/15.

Ministry of Education, Fiji, 2013. National Curriculum Framework, Suva: Government Printers.

Ministry of Education, Fiji, 2015. Ministry Reforms, http://www.education.gov.fi/images/OCTOBER/REFORMS.pdf

Moe, T., 2012. Special interest. Brookings Institution, Washington.

Moon, B.-K., 2012. Statement from the Secretary-General. http://www.globaleducationfirst.org/289.htm Accessed on 16/07/15.

Nabobo-Baba, U., 2006a. Teacher Education for New Times: Reconceptualizing Pedagogy and Learning in the Pacific. Directions: Journal of Educational Studies 28, 1\&2, 63-91. 
Nabobo-Baba, U., 2006b. Knowing and Learning: An Indigenous Approach, IPS Publications, PIAS-DG, University of the South Pacific, Suva.

Nabobo-Baba, U., 2008. Decolonizing Framings in Pacific Research: Indigenous Fijian Vanua research Framework as an organic response. ALTERNative 4, 2, 140-154.

Naisilisili, S., 2012. Ilivatu: An exploratory Study of Cu'u Indigenous Knowledge and Implications for Fijian Education, Unpublished thesis, University of the South Pacific, Suva.

Negroponte, $\quad$ N., $2006 . \quad$ One laptop per child. http://www.ted.com/talks/nicholas negroponte on one laptop per child?language=en Accessed on 16/07/15.

OECD, 2010. PISA 2009 Results: Overcoming Social Background: Equity in Learning, Opportunities and Outcomes (Volume II). OECD Publishing, Paris.

'Otunuku, M., 2011. Talanoa: how can it be used effectively as an indigenous research methodology with Tongan people? Pacific Asian Education 23, 2, 43-52.

Ozga, J., 2012. Comparison as a governing technology: the case of PISA." Research Intelligence $1,19,18-19$.

Pacific Island Forum Secretariat, 2009. Pacific Education \& Development Framework. PIFS, Suva.

Pacific Island Forum Secretariat, 2011. Pacific Regional MDGs Tracking Report. PIFS, Suva.

Pacific Island Forum Secretariat, 2012. Forum Education Ministers Meeting, Session 6, Paper 3, Pacific Benchmarking the quality of education for results (PaBER) - an update, May 14 15, 2012.

Ruru, D., 2010. Strengthening the effectiveness of aid delivery in teacher education: A Fiji case study. Unpublished PhD thesis, Victoria University of Wellington.

Saito, E., Tsukui, A., and Tanaka, Y., 2008. Problems on professional development of primary teachers in Vietnam: Case of Bac Gian Province. International Journal of Educational Development 28, 1, 89-103.

Schweisfurth, M., 2011. Learner-centred education in developing country contexts: From solution to problem? International Journal of Educational Development 31, 5, 425-432.

Sharma, A., Coombs, S., Chandra, S. and Sagaitu, M., 2015. Fiji: Evolution of education from colonial to modern times. In Crossley, M., Hancock, G. and Sprague, T. (Eds.), Education in Australia, New Zealand and the Pacific. Bloomsbury, London.

Smith, L., 1999. Decolonizing Methodologies: Research and Indigenous Peoples, Zed, London.

Steiner-Khamsi, G., and Waldow, F. (Eds.), 2012. World Yearbook of Education 2012: Policy Borrowing and Lending in Education. Routledge, London.

Thaman, K., 2004. Le'o e peau: towards cultural and cognitive democracy in development in Pacific Island communities, Islands of the World VIII International Conference, Kinmen Island, Taiwan, November. 
Thaman, K., 2007. Teacher education and development with specific references to Oceania. Proceedings of the Redesigning Pedagogy: Culture, Knowledge and Understanding Conference, Singapore, May.

Thaman, K., 2008. Culture, teaching and learning with specific references to Oceania. Shimane-Yamaguchi Global Seminar 2008 Public keynote lecture 2.

Tuinamuana, K., 2002. Global discourses and local culture/s of practice: A study of policy and practice in secondary teacher education in Fiji. Unpublished PhD thesis, University of Edinburgh.

Tuinamuana, K., 2007. Reconstructing dominant paradigms of teacher education: Possibilities for pedagogical transformation in Fiji. Asia-Pacific Journal of Teacher Education $35,2,111-127$.

UN, 2015. Transforming Our World. Accessed 27/08/16 https://sustainabledevelopment.un.org/post2015/transformingourworld.

UNESCO, 1996. Learning: The Treasure Within. (The Delors' Report). UNESCO, Paris.

UNESCO-GMR, 2014. Education for all Global Monitoring Report 2014: Teaching and Learning. UNESCO, Paris.

USP, 2016. Quality Teachers and Teacher Education in Fiji. Identities, Challenges and Priorities. Education Policy Brief, The University of the South Pacific, Suva.

West, P. and Daniel, J., 2009. The Virtual University for Small States of the Commonwealth, Open Learning, 24, 1, 85-95.

\section{Acknowledgements}

This research was funded by the British Academy Small Grants Scheme SG132329 and the University of the South Pacific, Faculty of Arts Law and Education. Thanks are also extended to all participants who contributed to the study in Fiji, to Terra Sprague in Bristol and to the Fiji Ministry of Education, National Heritage, Culture and Arts for granting permission for the fieldwork and for engaging with the project throughout its lifetime.

\section{Appendix: Research Team Members}

Cresantia Frances Koya Vaka'uta, Senior Lecturer in Education, USP

Rosiana Lagi, Lecturer in Education, USP, Labasa Campus

Konai Helu Thaman, Professor in Teacher Education, USP

Ledua Waqailiti, Lecturer in Education, USP

Atelini Bai, Lecturer in Education, University of Fiji, Lautoka Campus

Satish Chand, Lecturer in Education, Fiji National University, Lautoka Campus

Asish Kumar, Secondary School Teacher \& USP Tutor in Education, Labasa Campus 
Michael Crossley, Professor of Comparative and International Education, University of Bristol, UK

Simon McGrath, Professor International Education and Development, University of Nottingham, UK 